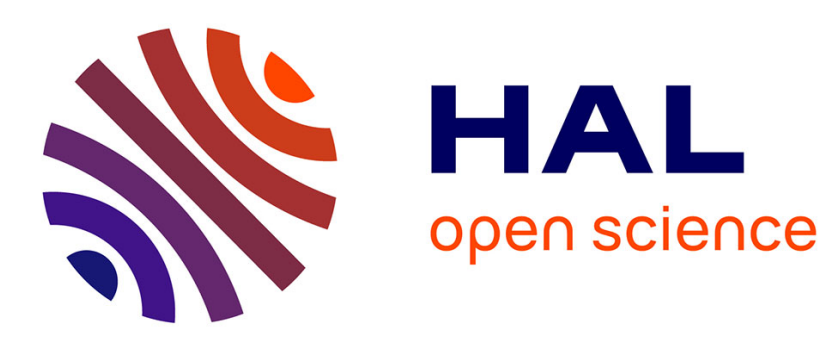

\title{
High immunogenic potential of p53 mRNA-transfected dendritic cells in patients with primary breast cancer
}

Özcan Met, Eva Balslev, Henrik Flyger, Inge Marie Svane

\section{To cite this version:}

Özcan Met, Eva Balslev, Henrik Flyger, Inge Marie Svane. High immunogenic potential of p53 mRNA-transfected dendritic cells in patients with primary breast cancer. Breast Cancer Research and Treatment, 2010, 125 (2), pp.395-406. 10.1007/s10549-010-0844-9 . hal-00555001

\section{HAL Id: hal-00555001 \\ https://hal.science/hal-00555001}

Submitted on 12 Jan 2011

HAL is a multi-disciplinary open access archive for the deposit and dissemination of scientific research documents, whether they are published or not. The documents may come from teaching and research institutions in France or abroad, or from public or private research centers.
L'archive ouverte pluridisciplinaire HAL, est destinée au dépôt et à la diffusion de documents scientifiques de niveau recherche, publiés ou non, émanant des établissements d'enseignement et de recherche français ou étrangers, des laboratoires publics ou privés. 


\title{
High immunogenic potential of p53 mRNA-transfected dendritic cells in patients with primary breast cancer
}

\author{
Özcan Met ${ }^{1,2 *}$, Eva Balslev ${ }^{3}$, Henrik Flyger ${ }^{4}$ Inge Marie Svane ${ }^{1,2}$; \\ ${ }^{1}$ Center for Cancer Immune Therapy (CCIT), Department of Hematology, ${ }^{2}$ Department of \\ Oncology, ${ }^{3}$ Department of Pathology and ${ }^{4}$ Department of Breast Surgery, University \\ Hospital Herlev, Copenhagen, Denmark
}

Running title: $\mathrm{T}$-cell response in breast cancer against p53-transfected DCs

*Correspondence:

Özcan Met

Center for Cancer Immune Therapy

Department of Hematology, 65Q9

University Hospital Herlev

Herlev Ringvej 75

Copenhagen, 2730 Herlev

Denmark

E-Mail: ozcmet01@ @eh.regionh.dk

Phone: +45 44884000 - 89229

Fax: +45 44884153 


\begin{abstract}
As pre-existent immunity might be a reflection of an emerging anticancer response, the demonstration of spontaneous $\mathrm{T}$-cell responses against tumor associated antigens (TAAs) in cancer patients may be beneficial before clinical development of DC-based cancer vaccines, because it will help identify likely responders to TAAs among patients who qualify and may benefit from this form of immune therapy. This study aimed to determine pre-existent $\mathrm{T}$-cell reactivity against the tumor suppressor protein $\mathrm{p} 53$ in breast cancer patients at the time point of primary diagnosis. After a short-term stimulation with autologous wt p53 mRNA-transfected DCs, IFN- $\gamma$ ELISPOT analysis revealed p53reactive $\mathrm{T}$ cells in the peripheral blood of more than $40 \%$ (15 of 36) of the tested patients. Both $\mathrm{CD} 4^{+}$and $\mathrm{CD} 8^{+}$p53-specific $\mathrm{T}$ cells secreted IFN- $\gamma$ after stimulation with $\mathrm{p} 53$ transfected DCs. Interestingly, more than $72 \%$ (13 of 18) of patients with high p53 ( $553^{\text {high }}$ ) expression in tumors were able to mount a p53-specific IFN- $\gamma$ T-cell response, in contrast to only $10 \%$ ( 1 of 10 ) of healthy donors and $11 \%$ ( 2 of 18 ) of patients with low or absent $\mathrm{p} 53\left(\mathrm{p} 53^{\text {low }}\right.$ ) expression in tumors. Furthermore, significantly higher secretion of IL-2 was detected in PBMCs after stimulation with p53-transfected DCs from patients with $\mathrm{p} 53^{\text {high }}$ tumor expression compared to patients with $\mathrm{p} 53^{\text {low }}$ tumor expression, whereas secretion of IL-10 was predominant in the latter group. The high frequency of spontaneous wt $\mathrm{p} 53$-reactive $\mathrm{T}$ cells detected in the peripheral blood of primary breast cancer patients with accumulation of p53 in tumor provides a rationale to consider DCs transfected with mRNA encoding wt p53 for clinical investigation in these patients.
\end{abstract}

Key words: dendritic cells; mRNA transfection; immunotherapy; breast cancer; tumor associated antigens

Abbreviations used: DCs, dendritic cells; TAAs, tumor associated antigens; PBMCs, peripheral blood mononuclear cells; MFI, mean fluorescence intensity; ELISPOT, enzyme-linked immunosorbent spot; $\mathrm{BCP}$, breast cancer patients; HD, healthy donors; Abs, antibodies 


\section{Introduction}

The re-emerging view of cancer immunosurveillance is based on findings that malignant tumors can be naturally recognized by the host's immune system and induce spontaneous tumor associated antigen (TAA)-specific T-cell responses [1,2]. Over the last decade, DCs have been subject to intense investigation as cellular adjuvant in cancer vaccines, based on the discovery that vaccination with DCs charged with TAAs is a potent strategy to elicit protective immunity in tumor-bearings hosts [3]. The rationale behind DC-based vaccination approaches is to stimulate effective cytotoxic T-cell responses in cancer patients by isolating DCs from the patient, load them with TAAs and inject the antigenloaded cells back into the patient. This has been accomplished by incubating DCs with peptides, proteins or by transfecting the cells with DNA constructs. Another appealing approach is to engineer DCs to synthesize tumor epitopes endogenously by transfecting with mRNA encoding TAAs [4]. The use of electroporation to release mRNA as translatable genetic material provides excellent means of TAA transfer [5]. Information on the incidence and magnitude of TAA-specific immune responses is important for identifying which TAAs are naturally targeted by the immune system and for understanding why natural immunity fails to eradicate tumors. TAAs that either play a role in the oncogenic process or promote cancer cell survival are favorable immunotherapeutic targets [6]. Among the several dozen of such antigens, the tumor suppressor protein p53 is particularly attractive as it is essential for the maintenance of the non-tumorigenic phenotype of cells [7]. In addition, the resultant over-expression of $\mathrm{p} 53$, triggered by the prolonged half-life of $\mathrm{p} 53$ protein as a result of mutation in the $\mathrm{p} 53$ gene, provides multiple potentially immunogenic p53 epitopes, which can be exploited as a target in, for example, the immunotherapy of breast cancer [8]. Although studies have shown that breast cancer is an immunogenic tumor, information concerning the extent and prevalence of pre-existent TAA-specific T-cell responses in breast cancer patients remains contradictory [9-11]. This may be explained by the predominant focus on MHC-I and single peptide epitopes responses. Furthermore, it is very likely that tumor-specific immune responses, like responses against infectious diseases, consist of multiple effectors including $\mathrm{CD} 4^{+} \mathrm{T}$ cells, $\mathrm{CD} 8^{+} \mathrm{T}$ cells, and antibodies. Since transfection of DCs 
with TAA-encoding mRNA provides the possibility of presenting a broad spectrum of TAA epitopes and thus allows the determination of polyclonal T-cell responses against the transfected TAA, we therefore, tested for the presence and frequencies of p53-specific $\mathrm{T}$ cells in breast cancer patients at the time point of primary diagnosis. Our data suggest that wt p53 mRNA-transfected DCs could be a useful immunotherapeutic strategy particularly in breast cancer patients with p53 expressing tumors. 


\section{Materials and Methods}

\section{Patients and blood samples}

Blood samples were obtained after informed consent from patients with primary breast cancer before surgery. Patients enrolled in this study had not received any neoadjuvant or adjuvant chemotherapy, hormone therapy, or radiotherapy before sample collection. Peripheral blood mononuclear cells (PBMCs) from breast cancer patients were isolated from heparinized blood by Lymphoprep (Nycomed, Oslo, Norway) density centrifugation, washed twice with PBS and once with X-VIVO 15 (Lonza, Verviers, Belgium) prior to cryopreservation in human AB-serum (PAA, Pasching, Austria) and $10 \%$ DMSO. Aliquots of $1 \times 10^{7}$ cells $/ \mathrm{ml}$ were stored in $-140^{\circ} \mathrm{C}$ and were used as stimulators or responder cells in experiments. Viability of thawed cells was above $80 \%$. PBMCs from healthy donors were separated and cryopreserved as previously described [12].

\section{Generation of monocyte-derived DCs}

DCs were generated by plating thawed PBMCs in Nunclon dishes (Nunc, Biotech Line, Slangerup, Denmark) at $5 \times 10^{6}$ cells/well in culture medium consisting of X-VIVO 15 (Lonza) supplemented with 1\% glutamax and 5\% heat-inactivated human AB-serum (PAA). Cells were allowed to adhere for $1.5 \mathrm{~h}$ in $5 \% \mathrm{CO}_{2}$ at $37^{\circ} \mathrm{C}$, and nonadherent cells were removed. Adherent cells were washed and suspended in culture medium supplemented with $250 \mathrm{IU} / \mathrm{ml}$ rh-IL-4 (CellGenix, Freiburg, Germany) and $1000 \mathrm{IU} / \mathrm{ml}$ GM-CSF (CellGenix), and incubated for six days for differentiation of DCs. On day 6, a cocktail consisting of $1000 \mathrm{U} / \mathrm{ml}$ IL-1 $\beta$ (CellGenix), $1000 \mathrm{U} / \mathrm{ml}$ TNF- $\alpha$ (CellGenix), 1000 U/ml IL-6 and $1 \mu \mathrm{g} / \mathrm{ml} \mathrm{PGE}_{2}$ (Minprostin, Pharmacia/Pfizer, Ballerup, Denmark) was added to the cell culture and DCs were allowed to mature for $24 \mathrm{~h}$. Mature DCs [13] were electroporated the following day and used for experimental analysis as specified in the text. Alternatively, immature DCs were electroporated with mRNA day 7, transferred 
back to the culture with added maturation cocktail and used for experimental analysis as indicated.

\section{Production of in vitro transcribed mRNA}

The wt p53 cDNA from pCMV-p53 (Clontech-Takara Bio Europe, Paris, France) was cloned into pSP73-SphA64 (kindly provided by Professor E Gilboa, Duke University Medical Center, Durham, NC) using HindIII and EcoRI restriction sites. The pSP73$\mathrm{Sph} / \mathrm{p} 53 / \mathrm{A} 64$ plasmid was propagated in Escherichia coli competent cells (Invitrogen, Paisley, UK) and was purified using CompactPrep Plasmid Maxi Kit (Qiagen, Hilden, Germany). Prior to serving as DNA templates for in vitro transcription, pSP73$\mathrm{Sph} / \mathrm{p} 53 / \mathrm{A} 64$ was linearized with SpeI and purified using Wizard DNA Clean-Up System (Promega). The in vitro transcription was performed with mMESSAGE mMACHINE T7 Ultra kit (Ambion, Austin TX, USA) and mRNA was purified with MEGAclear kit (Ambion) according to the manufacturer's instructions. The mRNA length, concentration and purity were evaluated with the Agilent 2100 Bioanalyzer (Agilent Technologies, Palo Alto CA, USA), using RNA 6000 Nano LabChip Kit (Agilent Technologies) according to the manufacturer's instructions. Data analysis was performed with 2100 Bioanalyzer software (Agilent Technologies).

\section{Electroporation of DCs}

DCs were washed twice, suspended in Opti-MEM medium (Invitrogen) and adjusted to a final cell density of $5 \times 10^{6}$ cells $/ \mathrm{ml}$. The cell suspension $(250 \mu \mathrm{l})$ was preincubated in a 4$\mathrm{mm}$ gap electroporation cuvette for five min on ice. Ten $\mu \mathrm{g}$ of mRNA encoding p53 was transferred to the cuvette and DCs were pulsed using a BTX 830 square-wave electroporator (Harvard Apparatus, Holliston MA, USA). Electroporation settings were adjusted to a single pulse, $500 \mathrm{~V}, 2 \mathrm{~ms}$. After electroporation, DCs were rested in $37^{\circ} \mathrm{C}$ and subsequently transferred to prewarmed culture medium supplemented with GM-CSF and IL-4 with or without maturation cocktail as described above. Transfected DCs [12] were further incubated in humidified atmosphere with $5 \% \mathrm{CO}_{2}$ and used for experimental 
analysis as specified in the text. All mock-transfected DCs used as controls underwent electroporation following the same conditions as described above.

\section{Flow cytometric analysis}

Messenger RNA-transfected DCs generated from healthy donors were checked for p53expression by intracellular FACS. After electroporation, DCs were permeabilized with Cytofix/Cytoperm solution (BD Biosciences, San Jose CA, USA) and stained with antibodies according to manufacturer's instructions. FITC conjugated mouse-anti-human p53 (Abcam, Cambridge, UK) antibody were used for detection of p53 protein in mRNAtransfected DCs. Mock-transfected DCs were also stained and used as negative control. Fluorescence analysis was performed with a FACSCalibur flow cytometer using Cell Quest software (BD BioSciences). The expression level (MFI) was determined as the ratio of the relative MFI of DCs electroporated with p53 mRNA divided by the relative MFI of mock-electroporated DCs.

\section{Immunohistochemical staining for p53}

Sections of formalin-fixed, paraffin-embedded tissue from the primary breast carcinoma were cut and stained with antibody against p53 DO7, (DAKO, Glostrup, Denmark), 1:50. In brief, the slides were immersed in citrate buffer solution for antigen retrieval and boiled in microwave for $10 \mathrm{~min}$ and washed in buffer solution (TBS). They were incubated with primary antibody for $1 \mathrm{~h}$ at room temperature and then washed in TBS. After $1 \mathrm{~h}$ of incubation in the secondary antibody, the sections were incubated with streptavidin-biotin-complex (DAKO). A multi-block including several different tissues was used for positive and negative controls. For estimation of positive reaction, only the strongly stained nuclei were counted as a percentage of all tumor nuclei. Less than 5\% were estimated as low p53 expression or as negative [14].

\section{Stimulation of p53-specific T cells}


DCs were transfected with p53 mRNA and used as stimulators in order to determine the presence and frequencies of p53-specific $\mathrm{T}$ cells in breast cancer patients. To extend the sensitivity of the ELISPOT assay, PBMCs were stimulated once in vitro before analysis [15]. Transfected DCs were cocultured with autologous PBMCs (nonadherent fraction after adherence step for DC generation) at a DC:PBMC ratio of 1:10. The following day, 40 units/ml IL-2 were added to the cultures and cells were tested for p53-reactivity in the ELISPOT assay on day 7. In other experiments (as specified in the text) $\mathrm{CD}^{+}$and $\mathrm{CD} 8^{+}$ T lymphocytes were purified from PBMCs by $\mathrm{CD} 4^{+}$and $\mathrm{CD} 8^{+} \mathrm{T}$ cell isolation kit (Miltenyi Biotec, Bergisch Gladbach, Germany) prior to stimulation with p53transfected DCs and IFN- $\gamma$ ELISPOT analysis as described above.

\section{ELISPOT assay}

The ELISPOT assay was used to quantify p53-specific IFN- $\gamma$-releasing effector T cells. Briefly, nitrocellulosebottomed 96-well plates (MultiScreen MAIP N4550, Millipore, Billerica MA, USA) were coated with anti-IFN- $\gamma$ Ab (1-D1 K; Mabtech, Nacka Strand, Sweden). The wells were washed, blocked with X-VIVO 15 medium and the effector T cells were added in duplicates at different cell concentrations. DCs transfected with p53 mRNA were added to the wells at a DC/T-cell ratio of 1:10. The plates were incubated overnight at $37^{\circ} \mathrm{C} / 5 \% \mathrm{CO}_{2}$. The following day, medium was discarded and the wells were washed prior to addition of biotinylated secondary Ab (7-B6-1-Biotin, Mabtech). The plates were incubated at room temperature (RT) for $2 \mathrm{~h}$, washed, and Streptavidin-ALP (Mabtech) was added to each well. Plates were incubated at RT for $1 \mathrm{~h}$ and the enzyme substrate BCIP/NBT ${ }^{\text {plus }}$ (Mabtech) was added to each well and incubated at RT for 5$10 \mathrm{~min}$. Upon appearance of dark purple spots, the reaction was terminated by washing with tap water. Spots were counted using ImmunoSpot 2.0 Analyzer (CTL, Cleveland $\mathrm{OH}, \mathrm{USA}$ ) and the frequency of $\mathrm{p} 53$-specific $\mathrm{T}$ cells were calculated from the number of spot-forming cells.

\section{Multiplexed ELISA (Luminex) assays}


PBMCs from eight patients with high p53 (p53 ${ }^{\text {high }}$ ) tumor expression and eight patients with low or absent p53 (p53 ${ }^{\text {low }}$ ) tumor expression were stimulated with p53-transfected DCs and supernatants from overnight ELISPOT cultures were collected and analyzed using the human Th1/Th2 5-plex panel kit (Invitrogen), which measured IFN- $\gamma$, IL-2, IL4, IL-5 and IL-10, and Luminex 200 (Luminex Corporation, Austin TX, USA) according to the manufacturer's instructions. PBMCs from eight healthy donors underwent same procedure as described above. Data analysis was performed with the STarStation v2.3 software (Applied Cytometry Systems, Sheffield, UK)

\section{Analysis of anti-p53 antibodies in serum}

p53-specific IgG titers were quantified using the commercially available p53 ELISA ${ }^{\text {PLUS }}$ (Autoantibody) Kit (Calbiochem/Merck Chemicals Ltd., Nottingham, UK) according to manufacturer's instructions and evaluated using at least four serial dilutions.

Results for each serum sample were calculated by determining the relative p53 index and internal controls provided by the manufacturers were used to establish a "cutoff" level ( $0.15 \mathrm{U}$ of $\mathrm{p} 53$ binding activity/ $\mu 1$ patient serum). Samples were always assayed in duplicate. Absorbance was determined on a spectrophotometer at a wavelength of 450 $\mathrm{nm}$ against a reference filter of $620 \mathrm{~nm}$ in order to compensate for differences in the material of the microtiter plate. Samples were designated positive for p53 antibody when the absorbance were $>20 \%$ cutoff value, whereas samples were designated negative for p53 antibody when the absorbance were $<$ cutoff value.

\section{Statistics}

Significant differences between sample means in ELISPOT and Luminex assays were determined with Mann-Whitney's test and results were considered significant when $\mathrm{p}<0.05$. Statistical analysis of the $\mathrm{p} 53$-specific IgG response in relation to IL-10 expression was carried out by a Fisher's exact test and results were considered significant when $\mathrm{p}<0.05$. 


\section{Results}

\section{Expression kinetic of p53 in DCs electroporated before or after maturation}

Before electroporation, the quality of the in vitro-transcribed wt p53 mRNA was analyzed with the Agilent 2100 Bioanalyzer. This system provides a more precise description of the integrity and quantity of the mRNA sample compared to the traditionally used agarose gel electrophoresis and spectrophotometry. Fig. 1a depicts the result of a representative electrophoretic chip run. The electropherogram and gel-like image provide data on size and concentration of mRNA, and also show the presence of degradation products in the mRNA sample. Only highly pure mRNA preparations were used for electroporation of DCs.

We then checked the expression profile of p53 protein by intracellular staining and flow cytometry in mature electroporated DCs or immature DCs electroporated prior to maturation. In DCs electroporated after maturation, the intracellular expression of p53 was substantial as early as $2 \mathrm{~h}$ after transfection, followed by an increased expression level which reached a maximum at $6 \mathrm{~h}$ post-transfection (Fig. 1b). The mean fluorescence intensity remained 3-4 folds higher in mature electroporated DCs at early time points (2-6 h) compared to DCs electroporated prior to maturation. At the time point of maximum intracellular expression, more than $95 \%$ of transfected DCs were stained positive for p53 expression (Fig. 1a, histogram plot). However, while the expression of p53 declined rapidly reaching an almost undetectable level $10 \mathrm{~h}$ after electroporation of mature DCs, a more sustained expression of p53 was observed in DCs electroporated before maturation, showing intermediate level expression of p53 $12 \mathrm{~h}$ post-transfection. The relatively high turn-over of p53 in transfected DCs is in marked contrast to the expression of enhanced green fluorescence protein (EGFP), often used as a model for TAAs in DC-transfection studies, which is stable 5 days after transfection [12].

\section{T-cell reactivity against p53 mRNA-transfected DCs in patients with primary breast cancer}


The presence of $\mathrm{T}$ cells specific for $\mathrm{p} 53$ in peripheral blood of primary breast cancer patients was determined at the time point of first diagnosis. For this purpose, PBMCs from both breast cancer patients and healthy donors were stimulated with autologous mature DCs transfected with p53 mRNA and p53-specific T cells were subsequently analyzed by ELISPOT IFN- $\gamma$ release assay. Before analysis, PBMCs were restimulated once in vitro to extend the sensitivity of the assay. Using this approach we were able to detect IFN- $\gamma$ T-cell reactivity against p53transfected DC targets in 15 of 36 breast cancer patients (Fig. 2a and b). In contrast, only one of 10 normal donors responded in this way to DCs transfected with p53 mRNA. These data suggest a high frequency of pre-existing cellular response in breast cancer patients against p53 at the time point of primary diagnosis.

To address which T-cell subpopulation was responsible for the secretion of IFN- $\gamma$, the Tcell populations from seven responder patients were each separated into $\mathrm{CD} 4^{+}$and $\mathrm{CD} 8^{+}$ $\mathrm{T}$-cell fractions by magnetic bead technology prior to stimulation with p53-transfected DCs and IFN- $\gamma$ ELISPOT analysis. The purity of $\mathrm{CD}^{+}$and $\mathrm{CD} 8^{+} \mathrm{T}$ cells was routinely found to be $>90 \%$ as assessed by flow cytometry (data not shown). ELISPOT analysis depicted in Fig. 2c demonstrates that both subtypes of p53-specific T cells secrete IFN- $\gamma$ after stimulation with DCs transfected with p53 mRNA.

\section{T-cell reactivity against $\mathrm{p} 53$ is associated with the accumulation of $\mathrm{p} 53$ in tumors from breast cancer patients}

Data from our previous phase II study showed a higher frequency of p53-expression in primary tumor samples from breast cancer patients attaining stable disease compared to patients with progressive disease during p53-targeted DC-vaccination therapy [16]. Accordingly, we questioned whether the accumulation of p53 in the tumor from breast cancer patients might influence the presence of IFN- $\gamma$ T-cell reactivity against p53 mRNA-transfected DCs. For this purpose, immunohistochemical staining was done to study the expression profile of p53 in surgically resected primary tumor specimens. Immunohistochemical analysis of two representative tumor specimens is shown in Fig. 
3a. We selected 18 patients with p53 ${ }^{\text {high }}$ tumor expression in tumors and 18 patients with p53 ${ }^{\text {low }}$ tumor expression, as measured by nuclear staining intensity (see Materials and methods) for evaluation of IFN- $\gamma$ T-cell reactivity against p53 mRNA-transfected DC targets. As depicted in Fig. 3c, 13 out of 18 patients with p53 $3^{\text {high }}$ expression in tumors had IFN- $\gamma$ T-cell reactivity against p53-transfected DCs in contrast to only two of 18 patients with $\mathrm{p} 53^{\text {low }}$ nuclear staining.

Thus, these data indicate that ex vivo IFN- $\gamma$ T-cell response to p53-transfected DCs is predominant in patients with over-expression of p53 in tumors.

\section{Cytokine profile of $\mathrm{T}$ cells in breast cancer patients with high or low/absent p53 expression in tumor}

We then analyzed whether T-cell reactivity against p53-transfected DCs was associated with a specific pattern of cytokine secretion. To this end, PBMCs from eight patients with p5 $3^{\text {high }}$ tumor expression and eight patients with $\mathrm{p} 53^{\text {low }}$ tumor expression were stimulated with p53-transfected DCs as described above. Supernatant were collected and analyzed with Multiplex Luminex cytokine assays. The assay demonstrated that p53-transfected DCs generally induced a significantly higher expression of the Th1-associated cytokine IL-2 (Fig 4a and Table 1) in PBMCs from patients with $\mathrm{p} 53^{\text {high }}$ expression in tumors compared to patients with $\mathrm{p} 53^{\text {low }}$ expression. In contrast, the secretion of IL-10 was more frequent in the group of patients with low or absent p53 expression (Fig. 4b). No significant difference of IL-4 and IL-5 secretion was detected among the patient groups (data not shown).

We also tested these patients for the presence of p53-specific IgG antibodies in serum. Four patients with $\mathrm{p} 53^{\text {high }}$ and only one patient with $\mathrm{p} 53^{\text {low }}$ tumor expression displayed p53-specific IgG serum antibodies (Table 1). Interestingly, the presence of p53-specific IgG antibodies correlated with in vitro secretion of IL-10 in patients with p53 ${ }^{\text {high }}$ tumors (Table $1 ; p=0.03$, Fisher's exact test). 


\section{Discussion}

The analysis of natural immune responses against TAAs in cancer patients is informative as it can help identify antigens to which tolerance induction is non-existent, incomplete or reversible. The prevalence of natural TAA-reactive T cells may also indicate that the immune system of the patient is responsive to the tumor and could potentially be exploited for tumor rejection [17]. Thus, such TAAs could be targeted in DC-based treatment strategies because it may be easier to expand a memory pool of $\mathrm{T}$ cells compared to generating new immunity. Data from a few selected patients suggest a favorable clinical course in patients with pre-existent TAA-directed immunity $[18,19]$. In this regard, pre-existing T-cell responses to p53 have been reported in cancer patients [20-22]. However, results have been conflicting with regard to the prevalence of preexisting TAA-directed T-cell responses in breast cancer [9-11, 23]. This might be due in part to a predominant focus on single peptide epitope responses. The use of overlapping peptide pools rather than single epitopes represents a more rational approach to analyzing naturally occurring TAA-specific T cells in cancer patients. We have recently conducted a phase II trial in which HLA-A2 ${ }^{+}$patients with progressive metastatic breast cancer were vaccinated with autologous DCs pulsed with a cocktail of 3 wild-type and 3 modified p53-peptides [16]. Yet, as mRNA-transfected DCs can induce a potent and broad (i.e. polyclonal) response, we used this method to assess the prevalence of pre-existing T-cell response against wt p53 in breast cancer patients at the time point of first diagnosis. After a short-term stimulation with mRNA-transfected mature DCs, IFN- $\gamma$ ELISPOT analyses revealed p53-reactive $\mathrm{T}$ cells in the peripheral blood of more than $40 \%$ of the tested patients. The $\mathrm{p} 53 \mathrm{~T}$ cell response was particular prevailing in patients with $\mathrm{p} 53^{\text {high }}$ expressing tumors. Several studies have shown higher frequency of TAA-specific T cells in cancer patients with tumor expressing antigens compared to patients with no TAA expression or healthy donors [24]. Our results demonstrate that even in early stage breast cancer patients with small operable tumors accumulation of p53 in the tumor results in the presence of relatively high frequencies of wt p53 epitope-specific T cells in the circulation. The underlying premise here is that the accumulation of $\mathrm{p} 53$ protein due to p53 mutation provides an opportunity for effective presentation of immunogenic wt p53 
epitopes to T cells and generation of wt p53-specific T cells in tumor-bearing hosts [7, 25]. While this may not always be the case, as indicated by results of Vierboom et al. and Hofmann et al. [20, 26]; in the present study, IFN- $\gamma$ responses to p53 mRNA-transfected DCs were detected in PBMCs of more than $72 \%$ of breast cancer patients with p53 ${ }^{\text {high }}$ expression in tumors. In contrast, only $10 \%$ of healthy donors and $11 \%$ of patients with p53 ${ }^{\text {low }}$ expression in tumors possessed this p53-specific reactivity. Because p53 is a ubiquitous expressed protein [7] it is conceivable that a certain threshold level of intracellular p53 protein must be exceeded in order to generate a p53-specific IFN- $\gamma$ response. However, although our data suggest that the expression levels of p53 are clearly above this threshold in patients with over-expression of p53 in tumors, no direct correlation to the distinct expression level was detected. The results support data from our previous phase II study which showed a higher frequency of p53 expression in the primary tumor samples from breast cancer patients attaining stable disease during p53 targeted DC therapy [16].

Unfortunately, because of sparse sample material, we were not able to address the phenotype of the p53-specific T cells. However, the low frequency of p53-specific T-cell response in healthy donors suggests that an antigen experienced phenotype is elicited by tumor-driven immune activation [27, 28]. Although our data demonstrate that breast cancer patients can elicit strong immune responses, it is also apparent that these responses are not necessarily protective against tumor progression. What determines the variation among cancer patients in terms of efficacy and intensity of antitumor immunity remains to be elucidated and could be related to mechanisms such as the action of regulatory $\mathrm{T}$ cells [29], Fas-mediated apoptosis induction in CTLs [30] and antigen down-regulation by the tumor [31]. Further investigation is required to more accurately define the level of p53 protein expression in tumors necessary for T-cell recognition and activation. Doing so, will help to identify likely responders to p53 epitopes on transfected DCs and thereby to select patients that may benefit from this form of immune therapy.

In a previous work [32], Nikitina et al. transduced DCs with p53 gene using an adenovirus vector and were able to stimulate anti-p53 $\mathrm{T}$ cell response in eight of nine patients with advanced stages of lung or head and neck cancer. The authors also demonstrated highly specific T-cell responses against tumors with accumulation of p53. 
Still, even though this strategy appears to be efficient, it may also have negative impact on DC functions including the risk of integration of viral gene into the host genome. In addition, immunodominant viral products could suppress an immune response against the transgene, which also restricts the application of multi-vaccinations [33].

Our data also show that upon activation with p53-transfected DCs, the secretion of the Th1-associated cytokine IL-2 was considerably more prevalent in patients with $\mathrm{p} 53^{\text {high }}$ expression in tumors compared to patients with $\mathrm{p} 53^{\text {low }}$ expression. In contrast, significantly higher secretion of the Th2-associated cytokine IL-10 was detected in patients with $\mathrm{p} 53^{\text {low }}$ tumor expression. The latter finding was unexpected and could be explained by lack of sufficient amounts of p53 for cross presentation which in turn may fail to induce immediate effector functions mediated by CTLs resulting in the predominance of the Th2 arm of the p53-specific immune response (Spiotto MT et al. Immunity 2002). There was also a significant correlation between $\mathrm{p} 53$-specific IgG serum antibodies in patients which had an IL-10 response when stimulated with p53 mRNA-transfected DCs but, surprisingly this correlation was only found in patients with $\mathrm{p} 53^{\text {high }}$ tumor expression, whereas, only one of the seven IL-10 responsive $\mathrm{p} 53^{\text {low }}$ patients possessed p53 antibodies. Clearly, more extensive studies need to be conducted in order to clarify any potential disease-associated $\mathrm{Th} 1 / \mathrm{Th} 2$ bias in response to p53-transfected DCs in patients with $\mathrm{p} 53^{\text {high }}$ compared to $\mathrm{p} 53^{\text {low }}$ tumor expression.

It has previously been shown that antibodies against p53 are associated with a poor prognosis [34]. Reconciling with this, immunotherapeutic approaches that are able to shift the balance towards Th1 polarization may be essential for more effective immunotherapy in patients with advanced disease [35, 36].

Several studies clearly indicates that an optimal antitumor immune response will require the concomitant activation of both the $\mathrm{CD} 4^{+}$and $\mathrm{CD} 8^{+} \mathrm{T}$-cell arm of the immune response $[37,38]$. Thus, a potential drawback of mRNA transfection of DCs could be that the endogenously expressed antigens derived from the transfected mRNA are preferentially channeled into the MHC-I processing pathway and activate $\mathrm{CD} 8^{+}$but not $\mathrm{CD}^{+} \mathrm{T}$ cells. As a result, vaccination with mRNA-transfected DCs would be deficient in the stimulation of the $\mathrm{CD} 4^{+} \mathrm{T}$-cell arm of the immune response [39]. However, recently it 
was shown that this is not necessarily the case. Müller et al. were able to induce breast cancer-specific $\mathrm{CD}^{+}$in addition to $\mathrm{CD}^{+} \mathrm{T}$ cells by transfecting DCs with tumor RNA [40]. Kyte et al vaccinated melanoma patients with DCs transfected with autologous tumor mRNA and demonstrated both $\mathrm{CD}^{+}$and $\mathrm{CD}^{+} \mathrm{T}$-cell responses [41]. In line with these reports, our results demonstrate that mRNA-transfected DCs induce p53-specific $\mathrm{CD}^{+}$and $\mathrm{CD}^{+} \mathrm{T}$ cells in patients with primary breast cancer. The molecular mechanisms by which endogenously processed peptides enter the MHC-II presentation pathway are still elusive. It has been proposed that autophagy might be the responsible mechanism for direction of cytosolic antigen onto class II molecules [42].

The presence of both $\mathrm{p} 53$-specific $\mathrm{CD} 8{ }^{+}$and $\mathrm{CD} 4{ }^{+} \mathrm{T}$ cells indicates that a coordinated immune response is being elicited in breast cancer patients, but that the response may be too limited to be effective.

The sequence of antigen loading and DC maturation ex vivo is also an important variable for optimizing mRNA-based gene transfer into DCs; however, the published data on this issue are conflicting. Initially, mRNA transfection of DCs was based on the presumption that electroporation of DCs prior to maturation was a prerequisite for optimal antigen presentation since immature DCs are specialized for antigen uptake [5, 43, 44]. Subsequent studies have highlighted that DCs electroporated after maturation were at least as efficient in antigen presentation and had even greater potency to invoke immune response than DCs electroporated before maturation $[12,45,46]$. We further expand on these reports by showing a 3-4 fold higher intracellular expression of p53 in DCs electroporated after maturation at all time points before maximum expression compared to DCs electroporated prior to maturation. However, expression of p53 persisted for a longer period in DCs electroporated before maturation and was readily detectable $12 \mathrm{~h}$ post-transfection. The expression of p53 was undetectable $24 \mathrm{~h}$ after transfection in all electroporated DCs.

Numerous studies have demonstrated a correlation between antigen persistence in the DC and magnitude of the immune response [47-49]. It takes at least several hours for the injected DCs to reach the lymph nodes, and even then, continued presentation of antigen is necessary for inducing an effective antitumor response [50, 51]. The majority of 
clinical trials have used a cytokine cocktail including TNF- $\alpha$, Il- $\beta$, IL-6 and PGE 2 to achieve full maturation of DCs and this process usually takes more than $24 \mathrm{~h}$. Given that the intracellular expression of p53 in DCs was absent $24 \mathrm{~h}$ after transfection, the use of DCs electroporated before maturation, which requires additional maturation culture for minimum $24 \mathrm{~h}$, might lead to reduced T-cell stimulatory capacity, because of the shortened duration of antigen presentation in vivo. In contrast, DCs electroporated after maturation offer the advantage of providing a supply of antigen over a sufficient period of time in vivo, as high level of intracellular TAA expression were detected in DCs $6 \mathrm{~h}$ post-transfection. In accordance with these results, this study supports the notion of introducing mRNA into mature DCs in a clinical vaccine regime.

In summary, to our knowledge this study is the first to report high frequency of preexisting T-cell response in p53 positive breast cancer patients at the time point of primary diagnosis by mRNA-transfected DCs. The scrutinization of pre-existent immune responses to TAAs in cancer patients could lead to a better understanding of how tumors interact and escape natural immunity. These data provide a rationale to consider DCs transfected with mRNA encoding p53 for clinical investigation in breast cancer patients with high expression of p53 in tumor.

\section{Disclosures}

The authors have no financial conflicts of interest.

\section{Acknowledgements}

The authors would like to thank the steering committee at Herlev Hospital, Denmark for access to patient material from the local biobank MAMBIO.

We thank E. Gilboa (Duke University Medical Center, Durham, NC, USA) for providing the pSP73-SphA64 plasmid used in this study. This work was supported by the Aase and Ejnar Danielsens Foundation and by various grants from Cancerfonden, Grosserer L. F. Foghts and Grosserer Valdemar Foersom og Hustru Foundations. 


\section{Reference List}

1. Dunn GP, Bruce AT, Ikeda H, Old LJ, Schreiber RD (2002) Cancer immunoediting: from immunosurveillance to tumor escape. Nat Immunol 3: 991 998.

2. van der BP, Zhang Y, Chaux P et al (2002) Tumor-specific shared antigenic peptides recognized by human T cells. Immunol Rev 188: 51-64.

3. Tacken PJ, de Vries IJ, Torensma R, Figdor CG (2007) Dendritic-cell immunotherapy: from ex vivo loading to in vivo targeting. Nat Rev Immunol 7: 790-802.

4. Van Tendeloo VF, Ponsaerts P, Berneman ZN (2007) mRNA-based gene transfer as a tool for gene and cell therapy. Curr Opin Mol Ther 9: 423-431.

5. Van Tendeloo VF, Ponsaerts P, Lardon F et al (2001) Highly efficient gene delivery by mRNA electroporation in human hematopoietic cells: superiority to lipofection and passive pulsing of mRNA and to electroporation of plasmid cDNA for tumor antigen loading of dendritic cells. Blood 98: 49-56.

6. Kessler JH, Melief CJ (2007) Identification of T-cell epitopes for cancer immunotherapy. Leukemia 21: 1859-1874.

7. Theobald M, Biggs J, Dittmer D, Levine AJ, Sherman LA (1995) Targeting p53 as a general tumor antigen. Proc Natl Acad Sci U S A 92: 11993-11997.

8. DeLeo AB, Whiteside TL (2008) Development of multi-epitope vaccines targeting wild-type sequence p53 peptides. Expert Rev Vaccines 7: 1031-1040.

9. Disis ML, Knutson KL, Schiffman K, Rinn K, McNeel DG (2000) Pre-existent immunity to the HER-2/neu oncogenic protein in patients with HER-2/neu overexpressing breast and ovarian cancer. Breast Cancer Res Treat 62: 245-252.

10. Nagorsen D, Scheibenbogen C, Schaller G et al (2003) Differences in T-cell immunity toward tumor-associated antigens in colorectal cancer and breast cancer patients. Int J Cancer 105: 221-225.

11. Rentzsch C, Kayser S, Stumm S et al (2003) Evaluation of pre-existent immunity in patients with primary breast cancer: molecular and cellular assays to quantify antigen-specific T lymphocytes in peripheral blood mononuclear cells. Clin Cancer Res 9: 4376-4386.

12. Met O, Eriksen J, Svane IM (2008) Studies on mRNA electroporation of immature and mature dendritic cells: effects on their immunogenic potential. Mol Biotechnol 40: 151-160. 
13. Pedersen AE, Thorn M, Gad M et al (2005) Phenotypic and functional characterization of clinical grade dendritic cells generated from patients with advanced breast cancer for therapeutic vaccination. Scand J Immunol 61: 147-156.

14. Garcia-Tunon I, Ricote M, Ruiz A et al (2006) Cell cycle control related proteins (p53, p21, and Rb) and transforming growth factor beta (TGFbeta) in benign and carcinomatous (in situ and infiltrating) human breast: implications in malignant transformations. Cancer Invest 24: 119-125.

15. McCutcheon M, Wehner N, Wensky A et al (1997) A sensitive ELISPOT assay to detect low-frequency human T lymphocytes. J Immunol Methods 210: 149-166.

16. Svane IM, Pedersen AE, Johansen JS et al (2007) Vaccination with p53 peptidepulsed dendritic cells is associated with disease stabilization in patients with p53 expressing advanced breast cancer; monitoring of serum YKL-40 and IL-6 as response biomarkers. Cancer Immunol Immunother 56: 1485-1499.

17. Goodell V, Salazar LG, Urban N et al (2006) Antibody immunity to the p53 oncogenic protein is a prognostic indicator in ovarian cancer. J Clin Oncol 24: 762768 .

18. Valmori D, Scheibenbogen C, Dutoit V et al (2002) Circulating Tumor-reactive CD8(+) T cells in melanoma patients contain a CD45RA(+)CCR7(-) effector subset exerting ex vivo tumor-specific cytolytic activity. Cancer Res 62: 1743-1750.

19. Karanikas V, Colau D, Baurain JF et al (2001) High frequency of cytolytic T lymphocytes directed against a tumor-specific mutated antigen detectable with HLA tetramers in the blood of a lung carcinoma patient with long survival. Cancer Res 61: 3718-3724.

20. Hoffmann TK, Donnenberg AD, Finkelstein SD et al (2002) Frequencies of tetramer+ T cells specific for the wild-type sequence p53(264-272) peptide in the circulation of patients with head and neck cancer. Cancer Res 62: 3521-3529.

21. Chikamatsu K, Sakakura K, Takahashi G et al (2009) CD4+ T cell responses to HLA-DP5-restricted wild-type sequence p53 peptides in patients with head and neck cancer. Cancer Immunol Immunother.

22. van der Burg SH, de Cock K, Menon AG et al (2001) Long lasting p53-specific T cell memory responses in the absence of anti-p53 antibodies in patients with resected primary colorectal cancer. Eur J Immunol 31: 146-155.

23. Sotiropoulou PA, Perez SA, Voelter V et al (2003) Natural CD8+ T-cell responses against MHC class I epitopes of the HER-2/ neu oncoprotein in patients with epithelial tumors. Cancer Immunol Immunother 52: 771-779.

24. Lewis JD, Reilly BD, Bright RK (2003) Tumor-associated antigens: from discovery to immunity. Int Rev Immunol 22: 81-112. 
25. Gnjatic S, Cai Z, Viguier M et al (1998) Accumulation of the p53 protein allows recognition by human CTL of a wild-type p53 epitope presented by breast carcinomas and melanomas. J Immunol 160: 328-333.

26. Vierboom MP, Zwaveling S, Bos GMJ et al (2000) High steady-state levels of p53 are not a prerequisite for tumor eradication by wild-type p53-specific cytotoxic $\mathrm{T}$ lymphocytes. Cancer Res 60: 5508-5513.

27. Inokuma M, dela RC, Schmitt $\mathrm{C}$ et al (2007) Functional T cell responses to tumor antigens in breast cancer patients have a distinct phenotype and cytokine signature. J Immunol 179: 2627-2633.

28. Sommerfeldt N, Schutz F, Sohn C et al (2006) The shaping of a polyvalent and highly individual $\mathrm{T}$-cell repertoire in the bone marrow of breast cancer patients. Cancer Res 66: 8258-8265.

29. Nishikawa H, Kato T, Tanida $\mathrm{K}$ et al (2003) CD4+ CD25+ T cells responding to serologically defined autoantigens suppress antitumor immune responses. Proc Natl Acad Sci U S A 100: 10902-10906.

30. Okada K, Komuta K, Hashimoto S et al (2000) Frequency of apoptosis of tumorinfiltrating lymphocytes induced by fas counterattack in human colorectal carcinoma and its correlation with prognosis. Clin Cancer Res 6: 3560-3564.

31. Kurnick JT, Ramirez-Montagut T, Boyle LA et al (2001) A novel autocrine pathway of tumor escape from immune recognition: melanoma cell lines produce a soluble protein that diminishes expression of the gene encoding the melanocyte lineage melan-A/MART-1 antigen through down-modulation of its promoter. $\mathrm{J}$ Immunol 167: 1204-1211.

32. Nikitina EY, Clark JI, Van Beynen J et al (2001) Dendritic cells transduced with full-length wild-type p53 generate antitumor cytotoxic T lymphocytes from peripheral blood of cancer patients. Clin Cancer Res 7: 127-135.

33. Humrich J, Jenne L (2003) Viral vectors for dendritic cell-based immunotherapy. Curr Top Microbiol Immunol 276: 241-259.

34. Reuschenbach M, von Knebel DM, Wentzensen N (2009) A systematic review of humoral immune responses against tumor antigens. Cancer Immunol Immunother.

35. Vujanovic L, Ranieri E, Gambotto A et al (2006) IL-12p70 and IL-18 genemodified dendritic cells loaded with tumor antigen-derived peptides or recombinant protein effectively stimulate specific Type-1 CD4+ T-cell responses from normal donors and melanoma patients in vitro. Cancer Gene Ther 13: 798-805.

36. Minkis K, Kavanagh DG, Alter G et al (2008) Type 2 Bias of T cells expanded from the blood of melanoma patients switched to type 1 by IL-12p70 mRNAtransfected dendritic cells. Cancer Res 68: 9441-9450. 
37. Hung K, Hayashi R, Lafond-Walker A et al (1998) The central role of CD4(+) T cells in the antitumor immune response. J Exp Med 188: 2357-2368.

38. Pardoll DM, Topalian SL (1998) The role of CD4+ T cell responses in antitumor immunity. Curr Opin Immunol 10: 588-594.

39. Gilboa E, Vieweg J (2004) Cancer immunotherapy with mRNA-transfected dendritic cells. Immunol Rev 199: 251-263.

40. Muller MR, Grunebach F, Nencioni A, Brossart P (2003) Transfection of dendritic cells with RNA induces CD4- and CD8-mediated T cell immunity against breast carcinomas and reveals the immunodominance of presented $\mathrm{T}$ cell epitopes. $\mathrm{J}$ Immunol 170: 5892-5896.

41. Kyte JA, Kvalheim G, Aamdal S, Saeboe-Larssen S, Gaudernack G (2005) Preclinical full-scale evaluation of dendritic cells transfected with autologous tumor-mRNA for melanoma vaccination. Cancer Gene Ther 12: 579-591.

42. Nimmerjahn F, Milosevic S, Behrends U et al (2003) Major histocompatibility complex class II-restricted presentation of a cytosolic antigen by autophagy. Eur $\mathbf{J}$ Immunol 33: 1250-1259.

43. Kalady MF, Onaitis MW, Padilla KM et al (2002) Enhanced dendritic cell antigen presentation in RNA-based immunotherapy. J Surg Res 105: 17-24.

44. Nair SK, Boczkowski D, Morse M et al (1998) Induction of primary carcinoembryonic antigen (CEA)-specific cytotoxic T lymphocytes in vitro using human dendritic cells transfected with RNA. Nat Biotechnol 16: 364-369.

45. Schaft N, Dorrie J, Thumann P et al (2005) Generation of an optimized polyvalent monocyte-derived dendritic cell vaccine by transfecting defined RNAs after rather than before maturation. J Immunol 174: 3087-3097.

46. Javorovic M, Pohla H, Frankenberger B, Wolfel T, Schendel DJ (2005) RNA transfer by electroporation into mature dendritic cells leading to reactivation of effector-memory cytotoxic T lymphocytes: a quantitative analysis. Mol Ther 12: 734-743.

47. Wang RF, Wang HY (2002) Enhancement of antitumor immunity by prolonging antigen presentation on dendritic cells. Nat Biotechnol 20: 149-154.

48. He Y, Zhang J, Mi Z, Robbins P, Falo LD, Jr. (2005) Immunization with lentiviral vector-transduced dendritic cells induces strong and long-lasting $\mathrm{T}$ cell responses and therapeutic immunity. J Immunol 174: 3808-3817.

49. Ludewig B, McCoy K, Pericin M et al (2001) Rapid peptide turnover and inefficient presentation of exogenous antigen critically limit the activation of selfreactive CTL by dendritic cells. J Immunol 166: 3678-3687. 
50. Bachmann MF, Beerli RR, Agnellini P et al (2006) Long-lived memory CD8+ T cells are programmed by prolonged antigen exposure and low levels of cellular activation. Eur J Immunol 36: 842-854.

51. Busch DH, Kerksiek KM, Pamer EG (2000) Differing roles of inflammation and antigen in $\mathrm{T}$ cell proliferation and memory generation. J Immunol 164: 4063-4070. 

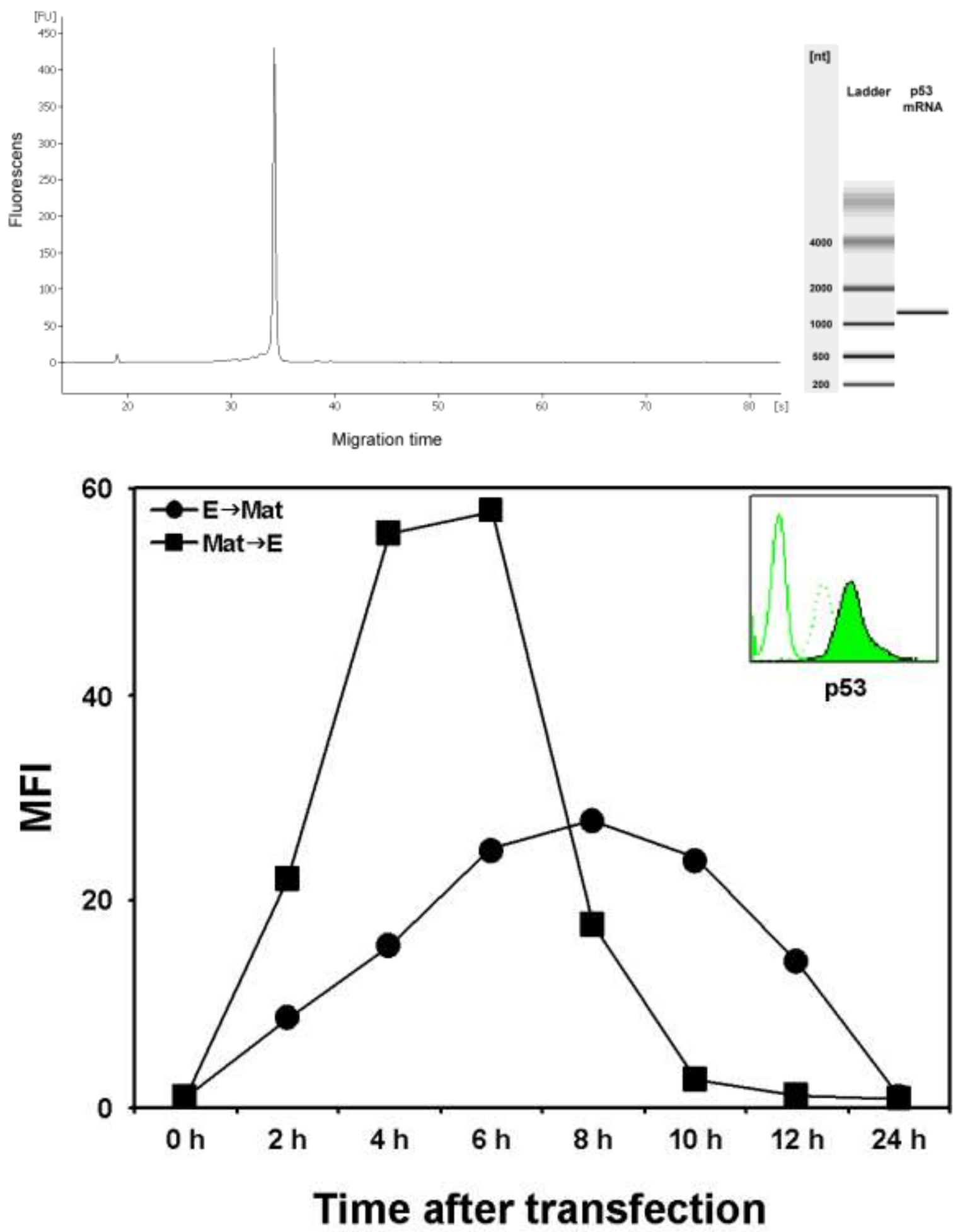


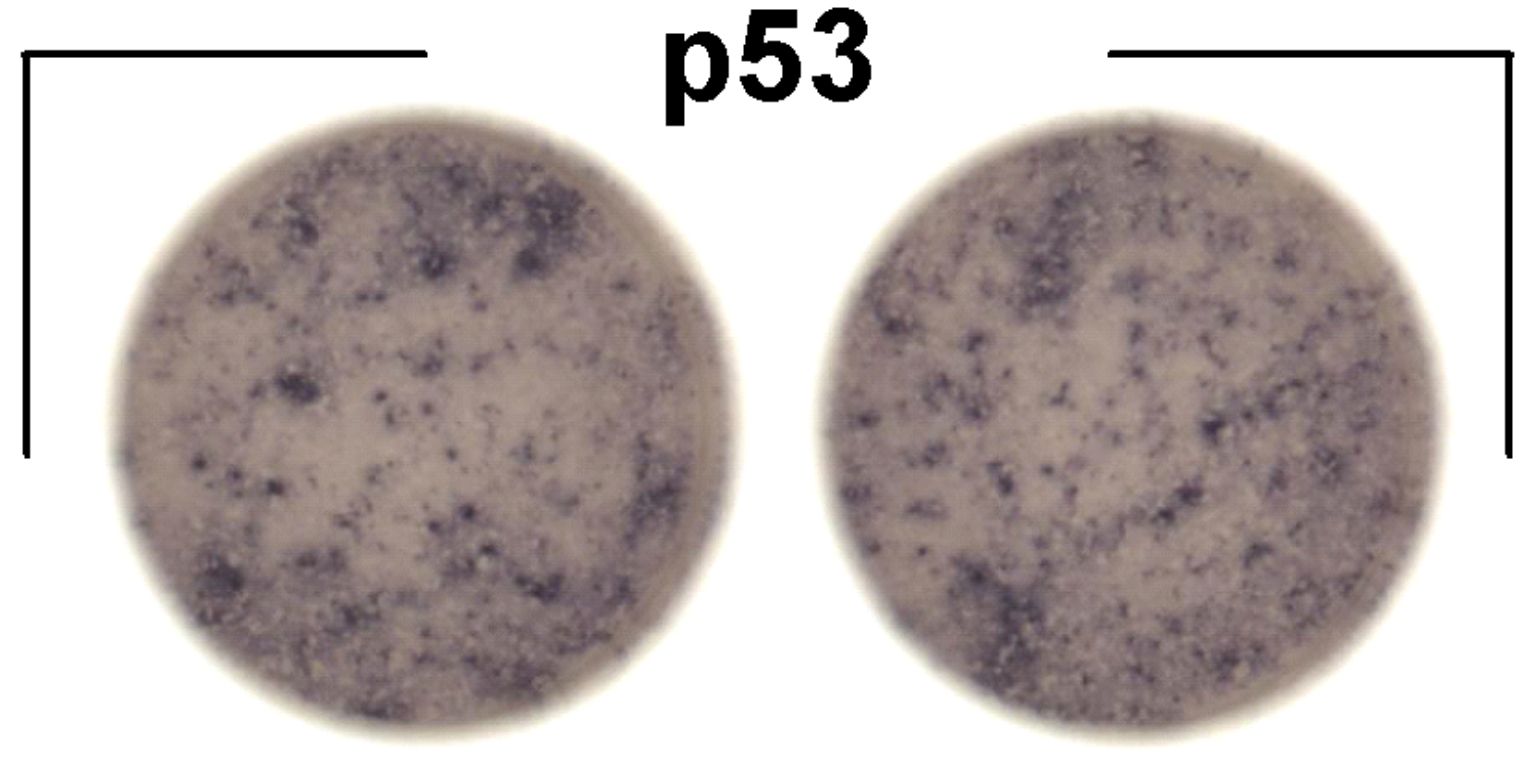

Mean number of spots $=\mathbf{2 5 3}$

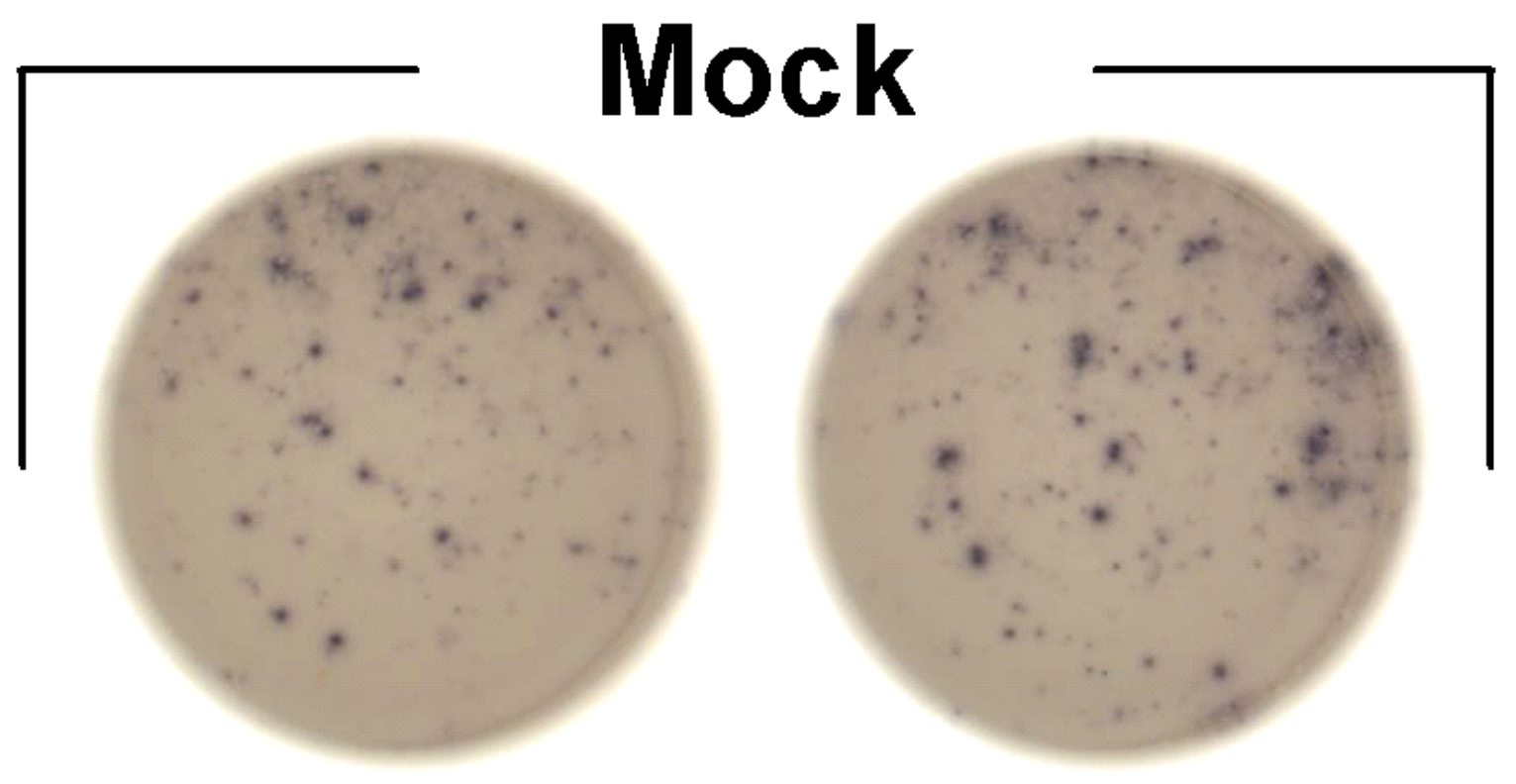

Mean number of spots $=\mathbf{8 0}$ 


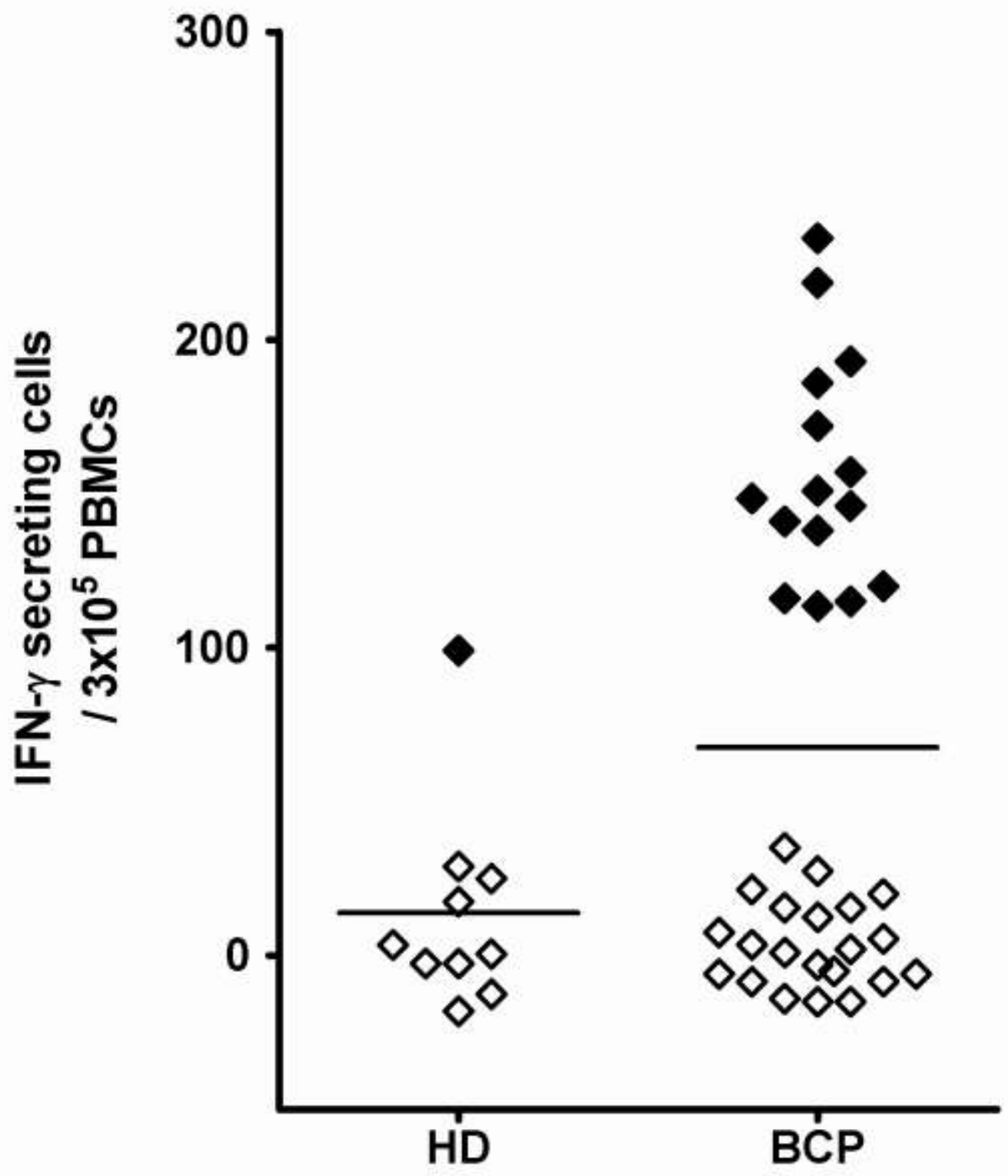



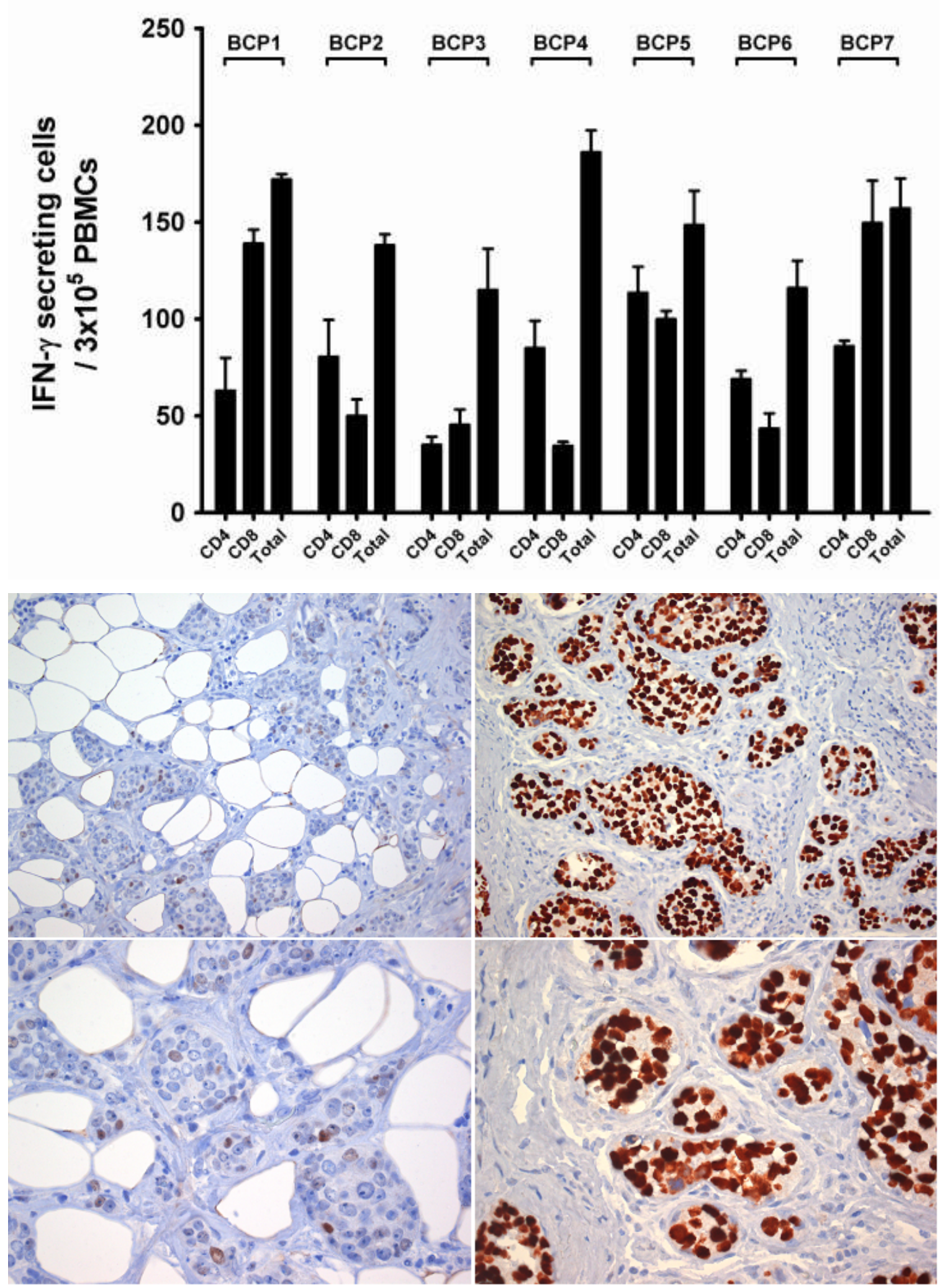


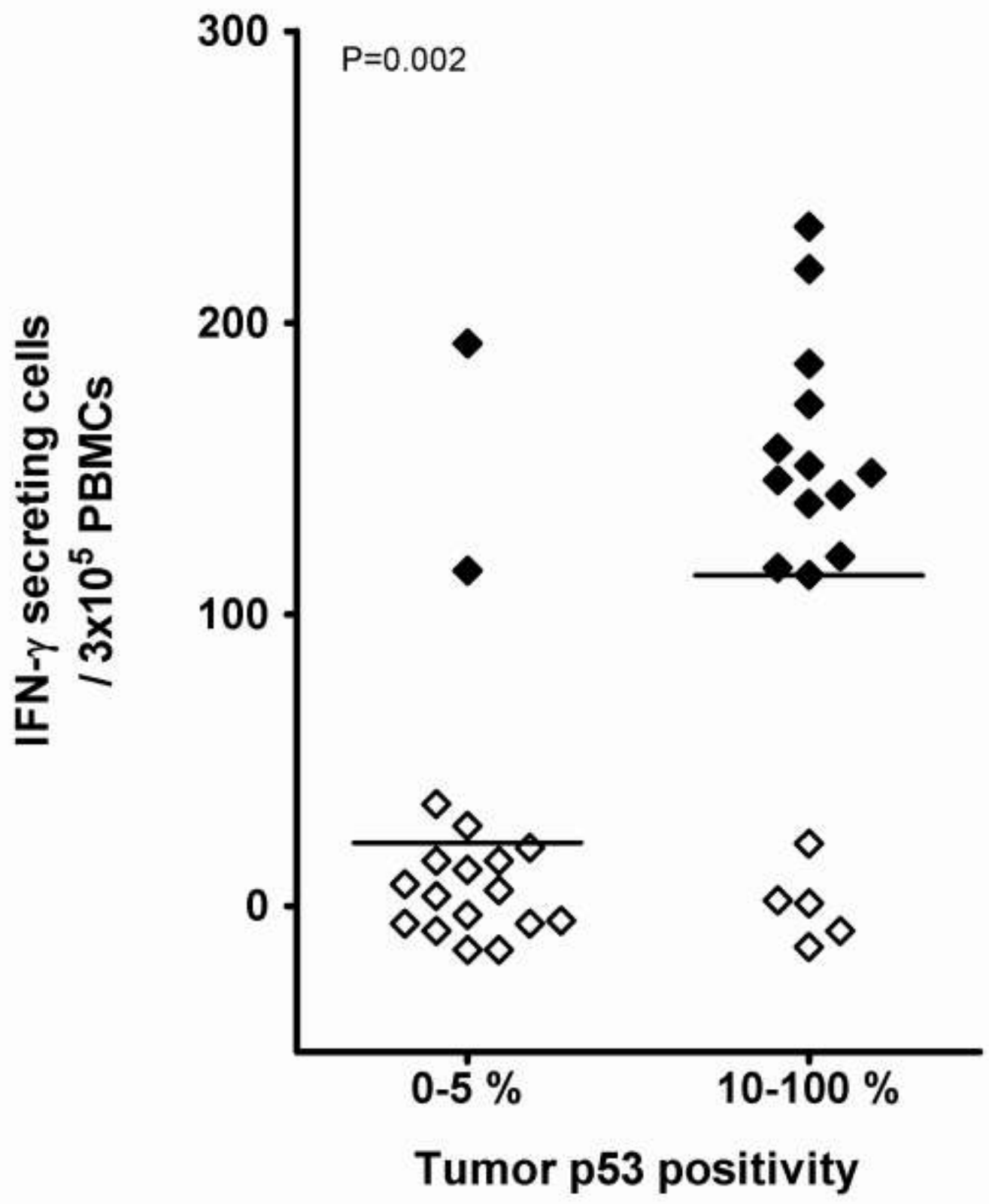




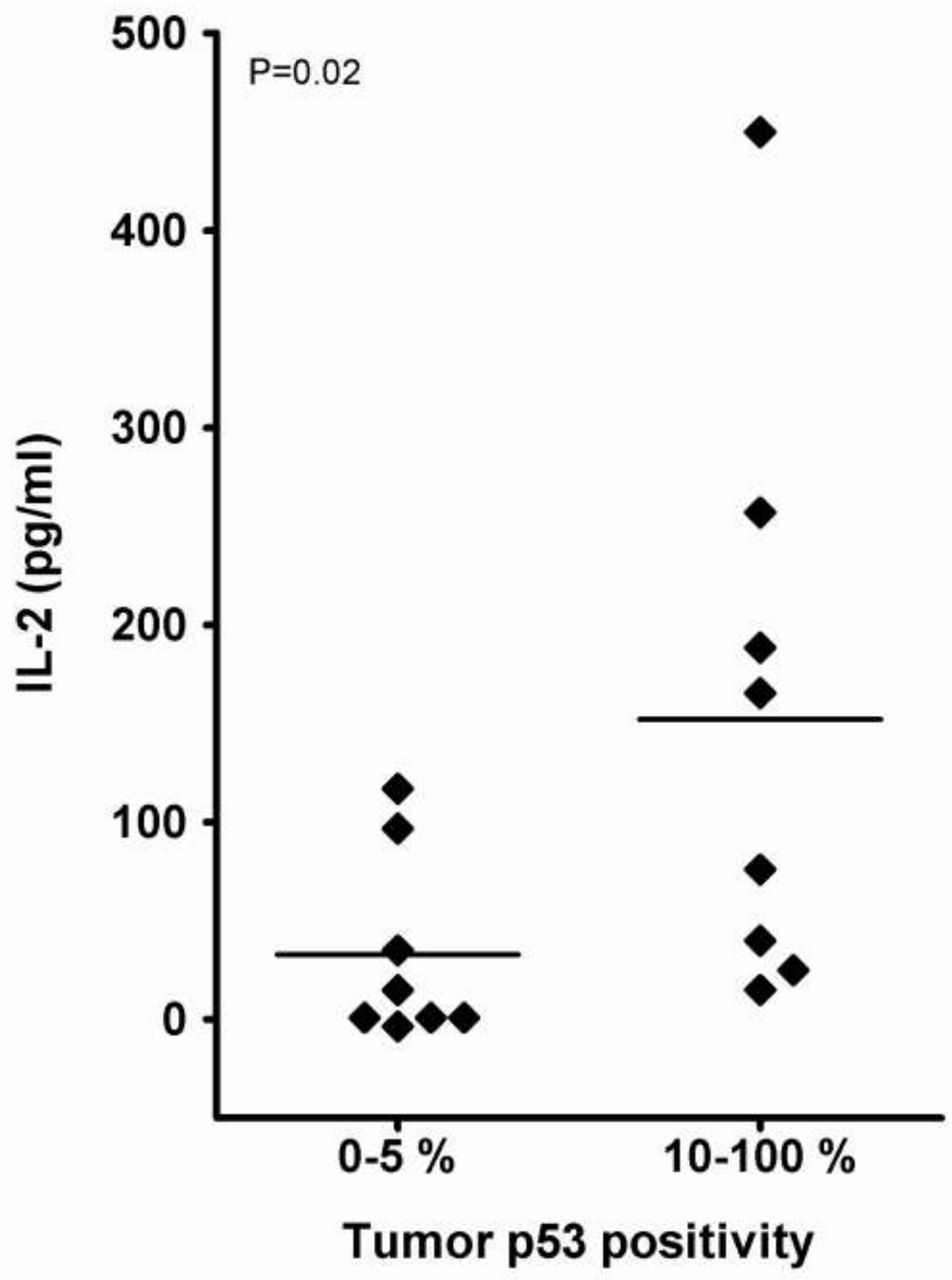




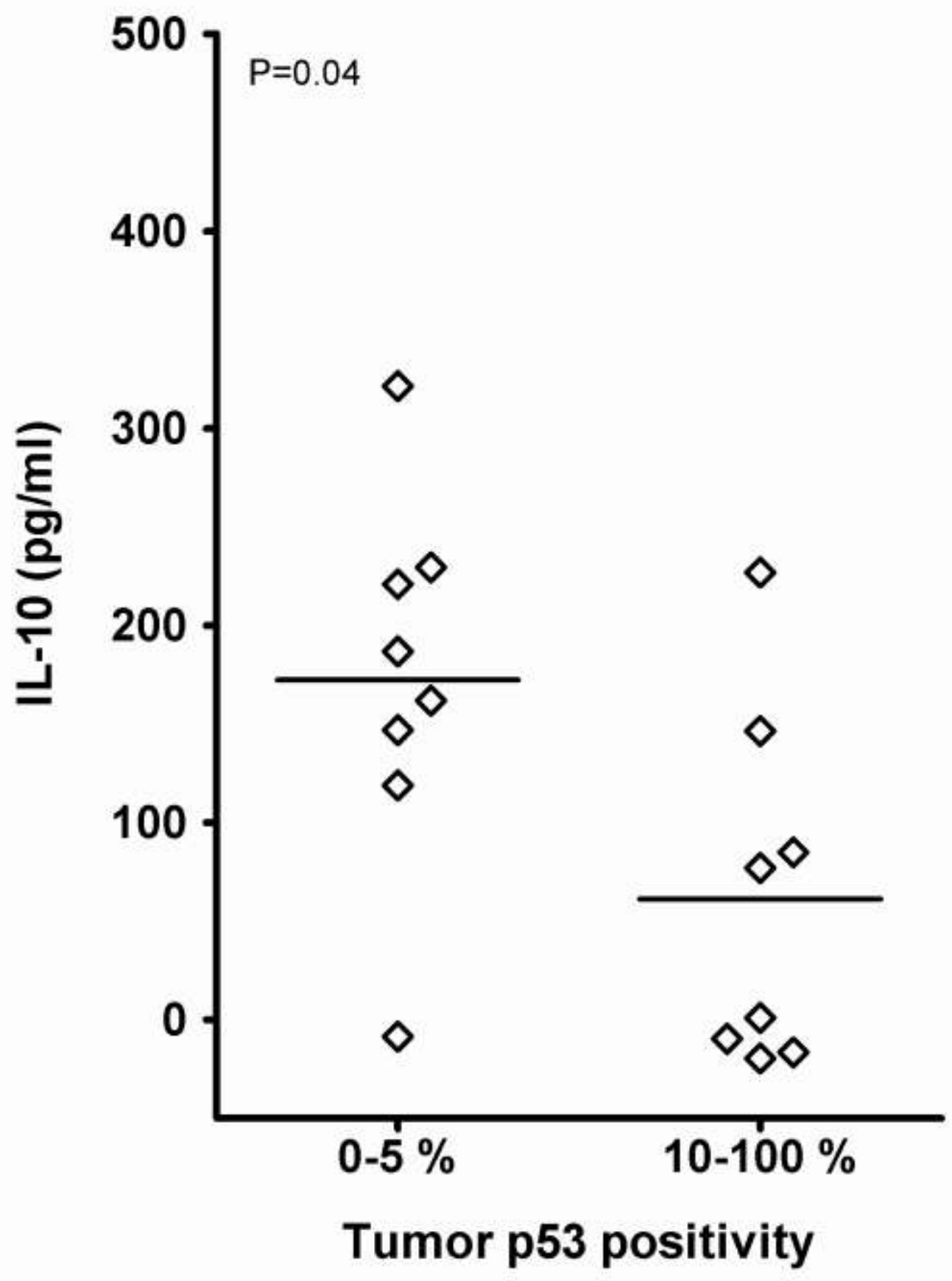

\section{Legends}

Fig 1. Quality control of p53 mRNA and expression kinetics of p53 protein in transfected DCs. The quality of the in vitro-transcribed mRNA was analyzed using the Agilent 2100 Bioanalyzer. $A$, an electropherogram and a gel-like image of p53 mRNA are shown. $B$, DCs were electroporated prior to maturation $(\mathrm{E} \rightarrow \mathrm{Mat}, \bullet)$ or after maturation $(\mathrm{Mat} \rightarrow \mathrm{E}, \mathbf{\square})$ with mRNA encoding p53. The intracellular expression profile of p53 protein in 
electroporated DCs was subsequently analyzed by flow cytometry at the indicated time points. The expression level (MFI) was determined as the ratio of the relative MFI of DCs electroporated with p53 mRNA divided by the relative MFI of mock-electroporated DCs. Flow cytometry histograms illustrate control mock-electroporated DCs (thin line), DCs electroporated prior to maturation (dashed line) or DCs electroporated after maturation (filled histogram) $6 \mathrm{~h}$ post-electroporation. The results are representative of three independent experiments.

Fig 2. Frequency of p53-reactive T cells in PBMCs from primary breast cancer patients. $A$, example of an ELISPOT response against wt p53 in PBMCs from a primary breast cancer patient (BCP). $B$, Thirty six patients and 10 healthy individuals were analyzed for p53-specific T-cell reactivity. PBMCs from BCP patients or from healthy individuals (HD) were stimulated with autologous DCs transfected with mRNA encoding p53 for 7 days prior to being plated overnight with autologous mRNA-transfected DCs, which served as targets for p53-specific T cells in the IFN- $\gamma$ ELISPOT assay. At all time, mocktransfected DCs were used as negative controls. The numbers of IFN $-\gamma$ secreting cells were calculated using an automated ELISPOT reader. Each diamond represents one individual. Responders (defined as average number of TAA-specific spots $>2 \mathrm{x}$ background) are marked as $\diamond$, whereas non-responding individuals are marked as $\diamond$. Data represents means of duplicates or triplicates with mock-specific IFN- $\gamma$ spots subtracted. $C, \mathrm{CD}^{+}$and $\mathrm{CD} 8^{+} \mathrm{T}$ cells from seven responder patients were isolated using magnetic bead technology and stimulated with autologous DCs transfected with p53 mRNA for 7 days prior to ELISPOT analysis. Each bar represents the mean spot number of triplicates +/- SD with mock-specific IFN- $\gamma$ spots subtracted.

Fig 3. T-cell reactivity against p53 is associated with the accumulation of p53 in tumor from breast cancer patients. $A$, immunohistochemical analysis of two representative tumor specimens are shown. A positive immunostaining of p53 appeared as a cytoplasmic and granular brown-colored staining. Top (20x) and bottom left (40x), tumor specimen with low or absent p53 expression $(<5 \%)$. Top $(20 \mathrm{x})$ and bottom right $(40 \mathrm{x})$, tumor specimen with high p53 expression $(>10 \%)$. B, PBMCs from 18 patients with high p53 tumor expression (10-100\%) and 18 patients with low or absent p53 tumor expression (0-5\%) were stimulated with autologous DCs transfected with p53 mRNA for 7 days prior to ELISPOT analysis. Each diamond represents one individual. Responders are marked as $\diamond$, whereas non-responding individuals are marked as $\diamond$. Data represents means of duplicates or triplicates with mock-specific IFN- $\gamma$ spots subtracted.

Fig 4. Multiplex cytokine assay of p53-reactive T cells in breast cancer patients with high or low/absent p53 expression in tumor. PBMCs from eight patients with high p53 expression in tumors and eight patients with low or absent p53 expression in tumors were stimulated with p53-transfected DCs for 7 days prior to ELISPOT analysis. Supernatants from overnight ELISPOT cultures were collected and analyzed for (A) IL-2 and (B) IL-10 secretion using Luminex 200. Each diamond represents one individual. Data represents means of duplicates or triplicates with background (mock-specific) subtracted. Straight 
lines represent median values. For both cytokines tested, the differences between patients with high p53 tumor expression and patients with low or absent p53 tumor expression were statistically significant $\mathrm{p}<0.05$ (Mann-Whitney).

Table 1. Summary of cytokine production in ELISPOT and Luminex assay of p53reactive $T$ cells and serum $\mathrm{p} 53$ antibodies in breast cancer patients.

ND: not determined 